\title{
Trends in Global Assisted Reproductive Technologies Research: a Scientometrics study
}

\author{
Maryam Okhovati ${ }^{1}$, Morteza Zare ${ }^{2}$, Fatemeh Zare ${ }^{3}$, Maliheh Sadat Bazrafshan ${ }^{4}$, Azam Bazrafshan ${ }^{5}$
}

${ }^{1}$ Ph.D. of Library and Information Science, Assistant Professor, Physiology Research Center, Institute of Neuropharmacology, Kerman University of Medical Sciences, Kerman, Iran

${ }^{2}$ M.Sc. of Epidemiology, Neuroscience Research Center, Institute of Neuropharmacology, Kerman University of Medical Sciences, Kerman, Iran

${ }^{3}$ Student of Pharmacy, School of Pharmacy, Shiraz University of Medical Sciences, Shiraz, Iran

${ }^{4}$ M.Sc. of Epidemiology, School of Public Health, Kerman University of Medical Sciences, Kerman, Iran

5 M.Sc. of Medical Library and Information Science, Neuroscience Research Center, Institute of Neuropharmacology, Kerman University of Medical Sciences, Kerman, Iran

\section{Type of article: Original}

\begin{abstract}
Introduction: This study illustrated the global contribution to assisted reproductive technologies (ARTs) research in MEDLINE database from 1998 to 2014.

Methods: In March 2015, the MEDLINE database was searched for research publications indexed under 'reproductive techniques, assisted' (including the following MeSH headings: in vitro fertilization [IVF]; intracytoplasmic sperm injections; cryopreservation; and ovulation induction), with the following expressions in the fields of title or abstract: intrauterine insemination; sperm donation; embryo/egg donation and surrogate mothers. The number of publications in MEDLINE database was recorded for each individual year, 1998-2014, and for each country. The following countries were arbitrarily selected for data retrieval: United States, United Kingdom, France, Germany, Canada, Italy, Japan (G7 countries), Brazil, Russia, India, China (BRIC countries), Egypt, Turkey, Israel and Iran.

Results: The absolute number of publications for each country from 1998 to 2014 ranged from 75 to 16453 , with a median of 2024. The top five countries were the US (16453 publications), the UK (5427 publications), Japan (4805), China (4660) and France (3795). ART (20277), cryopreservation (11623) and IVF (11209) were the most researched areas.

Conclusion: Global research on ARTs were geographically distributed and highly concentrated among the world's richest countries. Cryopreservation and IVF were the most productive research domains among ARTs.

Keywords: infertility, assisted reproductive technologies, bibliometrics

\section{Introduction}

Infertility is an important health problem, with an estimated prevalence of 48.5 million couples worldwide (1). Although infertility is mostly common in aging populations and in urban areas where women have their first child at an older age, the burden of infertility and its social consequences are predominantly found in developing and transitional countries (2). In response to the increasing rates of infertility, rapid progress in reproductive medicine and research has been largely attributed to significant developments and novel technologies in the treatment and care of infertile couples in the world (3). In this context, assisted reproductive technologies (ARTs) have been widely recommended as successful and common treatments in most countries. ARTs include a wide range of treatments or procedures involving in vitro handling of human oocytes, sperms or embryos for establishing a pregnancy(4). In vitro fertilization (IVF) and its extended technologies, such as intracytoplasmic sperm injection (ICSI), pre-
\end{abstract}

\section{Corresponding author:}

Azam Bazrafshan, Neuroscience Research Center, Institute of Neuropharmacology, Kerman University of Medical Sciences, Kerman, Iran. Tel: +98.3432263855, Fax:+98.3432263857, Email: Bazrafshan.a.83@gmail.com

Received: September 20, 2015, Accepted: November 21, 2015 , Published: December 2015

iThenticate screening: November 03, 2015, English editing: November 30, 2015, Quality control: December 01, 2015

(C) 2015 The Authors. This is an open access article under the terms of the Creative Commons Attribution-NonCommercialNoDerivs License, which permits use and distribution in any medium, provided the original work is properly cited, the use is non-commercial and no modifications or adaptations are made. 
implantation genetic diagnosis (PGD), and cryotechnology, are among the most common ARTs worldwide. It is estimated that more than half a million IVF cycles are performed annually in the European countries, resulting in 100,000 new-borns $(3,5,6)$. The total number of successful IVF and ICSI births worldwide was reported as 5 million cases in 2012 (7). With respect to worldwide recognition and increased demands for ART services, high quality research and key publications are still required to develop these technologies in developing countries. Although the number of journals and publications in the field of reproductive medicine has increased dramatically in recent years $(3,8)$, much regional and country variation is in progress. Global research on ARTs has been highly concentrated among the world's richest countries while developing countries have indicated the least contribution to the research on ARTs and reproductive technologies $(9,10)$. As research on ARTs has been distributed disproportionately among countries, further investigations are needed to explore these patterns between and within countries. Indeed, previous analyses have identified trends and the geographical distribution in the field of clinical reproductive medicine $(3,9,11)$. Collaboration networks $(12)$ and the most cited articles $(8,13$, 14) have also been investigated to some extent. Although research is the key driver for developing ARTs in communities, it has remained neglected or ranked low on national research priorities in developing countries (15). Therefore, national evaluations are required to evaluate the research productivity and its attributes for the purpose of making research policies and priorities within countries. In an attempt to address these challenges, the present study aimed to provide detailed information on global research publications on ARTs between 1998 and 2014 in the MEDLINE database. Further analysis has been made to compare the research performance between the leading countries in the field using bibliometric techniques. The present study illustrates the patterns of global research on infertility involving different technologies implemented for the purpose of treatment and care of infertile couples. It also helps obtain a comprehensive and up-to-date perspective of this field to better understand the contribution of international scientists to the global ART research. The present study's findings tend to help policymakers evaluate the research performance of scientists within and across borders.

\section{Material and Methods}

In March 2015, the MEDLINE database was searched for research publications indexed under the medical subject heading (MeSH) 'Reproductive Techniques, Assisted' (including the following MeSH headings: in vitro fertilization; intracytoplasmic sperm injections; cryopreservation; and ovulation induction), with the following expressions in the fields of title or abstract: intrauterine insemination; sperm donation; embryo/egg donation and surrogate mothers. The number of research publications in the MEDLINE database was recorded for each individual year, from 1998 to 2014, and for each country. The affiliation of the corresponding author was used to identify affiliation of a research publication to a country. The first year used for the search was 1998 to ensure the ability to retrieve reliable data on authors' and countries' affiliations from the MEDLINE database. The following countries were arbitrarily selected for data retrieval: United States, United Kingdom, France, Germany, Canada, Italy, Japan (G7 countries), Brazil, Russia, India, China (BRIC countries), Egypt, Turkey, Israel and Iran. Data for the global burden of infertility were extracted from the WHO disability-adjusted life-year (DALY) estimates for 2012. The semantic word mapping technique was implemented to identify major domains using VOSviewer software (version 16.0).

\section{Results}

3.1. Global Profile of ART Research

In total, 96,739 articles were published in the MEDLINE database between 1998 and 2014. Trends in global research publications on ARTs have shown that ART and cryopreservation experienced dramatic growth in the number of publications. The absolute number of research publications for each ART from 1998 to 2014 ranged from 71 (sperm donation) to 20277 (ART), with a median of 2451. The top techniques according to the absolute number of publications were ART (20277), IVF (11209), cryopreservation (11623), ovulation induction (4352), and ICSI (2960). The major research domains of selected countries in the field of ARTs are illustrated in Figure 1. In this graph, several clusters are identified using different colours.

\subsection{Comparison of Country Profiles}

The absolute number of research publications for each country from 1998 to 2014 ranged from 75 (Russia) to 11674 (US), with a median of 2024. The top five countries according to the absolute number of publications were the US (16453 publications), the UK (5427 publications), Japan (4805), China (4660) and France (3795). According to these data, the US is the major producer of ART research in the world, having many more publications than other 
countries. Figure 2 illustrates the distribution of the global burden of infertility and the share of research publications for selected countries. In this graph, the level of infertility's burden is illustrated through a range of colors.

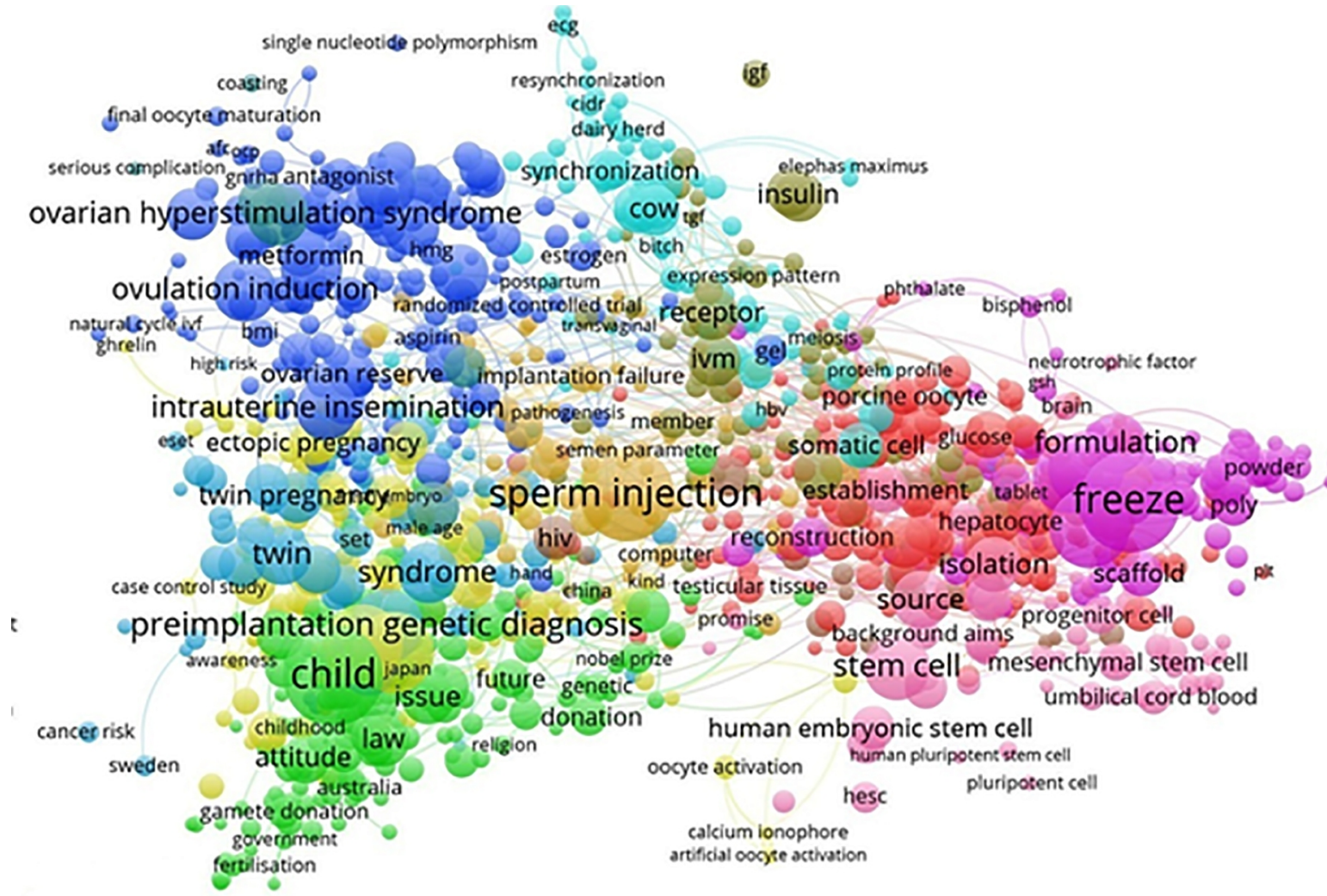

Figure 1. Major research domains of selected countries' publications for ARTs in MEDLINE database from 1998 to 2014; larger nodes indicate higher productivity

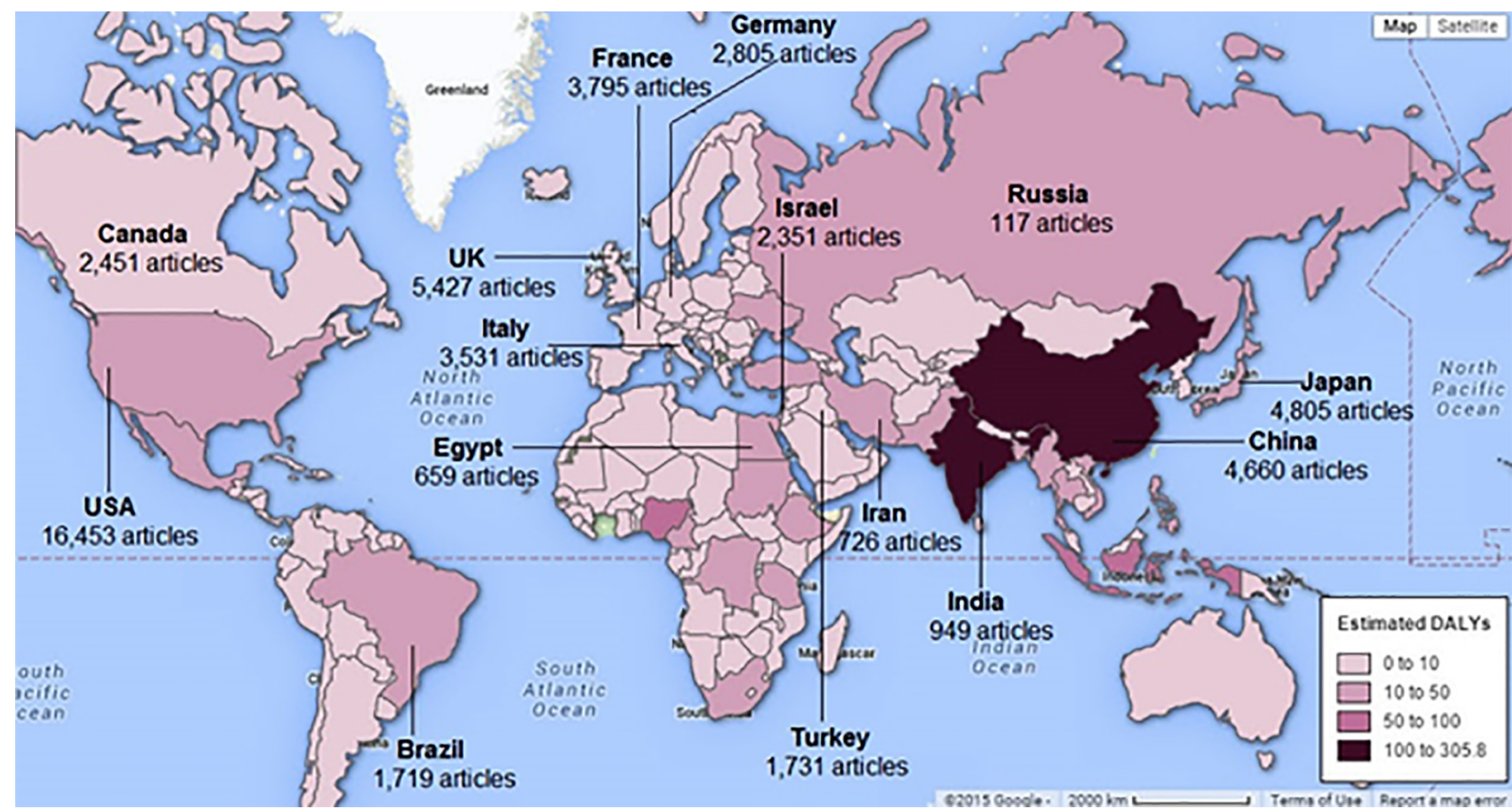

Figure 2. Global distribution of burden of infertility and the share of selected countries in the global ART research publications 


\section{Discussion}

The evaluation of the research literature in the ART field indicated regional and country variations. Global research on ARTs was geographically distributed and highly concentrated among the world's richest countries, particularly the US, the UK and Japan. Cryopreservation and IVF were the most productive research domains among ARTs. Further inspection of data indicated the major semantic clusters of research literature published by selected countries. According to our findings, the number of publications on ARTs increased dramatically between 1998 and 2014. This trend was previously observed in similar investigations $(3,11,16)$. However, this growth followed different patterns within different ART domains, as ART, IVF and cryopreservation indicated significant progress over the years. Our findings indicated that cryopreservation and IVF were the most productive research domains among ARTs. Preliminary investigations suggested that ART and IVF are the most cited research domains among reproductive medicine literature (3). These technologies, which enable scientists and physicians to use frozen stored sperm, oocytes, embryos, and testicular and ovarian tissues, are also among the most common and successful treatments in the world. The broad provision of these technologies has potentially increased the chance of extended research on these domains. These technologies also appeared among the most productive research domains according to previous studies. Although ART and IVF research literature indicated upward trends over the years, a detailed analysis revealed the global shift from developing new infertility interventions towards more in-depth analysis of the health implications for mothers and their children (3). However, further analysis is required to investigate the characteristics of other ARTs, such as egg or sperm donation, that are potentially restricted in some countries due to legal and social issues, particularly in developing and transitional countries. Our analysis also indicated the share of G7 and BRICs in the global ART research. These findings are consistent with early evidence suggesting that G7 countries are the major sources of ART research in the world (16). The highest level of research productivity has been reported by the United States, with a $21.82 \%$ share of the global output. The United Kingdom ranked second with $9.78 \%$, followed by Italy (7.98\%), Turkey $(5.19 \%)$ and China (4.33\%) (16).

This study has revealed many regional and country variations in the research literature published in the MEDLINE database. These variations might be explained by several reasons. Previous studies have indicated significant variations among the rich countries, especially in Europe, in ART research output due to legal restrictions affecting the practice of ARTs in some countries $(17,18)$. These restrictions have not only influenced the type of research performed, but also the amount of research data published (11). Other empirical studies have also suggested the availability of financial funding as a key driver of ART research in the world (11). For most developing countries, infertility services are not widely accessible or affordable. Although optimal utilization of IVF has been estimated to be around 1500 cycles per one million people per year, the provision of such services has declined significantly in developing countries (15). Indeed, the contribution of developing countries to global ART research has remained limited due to the lack of infrastructures and financial resources. In addition, infertility prevention, treatment and care have been neglected, ranking low on the research priorities, particularly in developing countries (15).

Further methodological considerations for this study should be noted. First, with current methodology, every publication is affiliated with a single (the corresponding) author. However, in the case of international collaborations, different countries are involved. This may underestimate the number of publications for each country. Next, our findings were limited to searches in the MEDLINE database. Searching other databases such as Scopus or Web of Science may lead to different results. However, MeSH headings are only available through the MEDLINE and PubMed interfaces.

\section{Conclusions}

In summary, global research on ARTs has been geographically distributed and highly concentrated among the world's richest countries. Cryopreservation and IVF have been the most productive research domains amongst ARTs. Further investigations into the causes and characteristics of less common ARTs research are required to foster ART research in developing countries.

Acknowledgments and financial disclosure:

The authors received no funding for this work.

Conflict of Interest:

There is no conflict of interest to be declared. 


\section{Authors' contributions:}

All authors contributed to this project and article equally. All authors read and approved the final manuscript.

\section{References}

1) Mascarenhas MN, Flaxman SR, Boerma $T$, Vanderpoel S, Stevens GA. National, regional, and global trends in infertility prevalence since 1990: a systematic analysis of 277 health surveys. Plos One. 2012;9(12):e1001356. Doi: 10.1371/journal.pmed.1001356. PMID: 23271957. PMCID: PMC35255272.

2) World Health O. Preconception Care to Reduce Maternal and Childhood Mortality and Morbidity. Geneva (CH): World Health Organization. 2012.

3) Aleixandre-Benavent R, Simon C, Fauser BCJM. Trends in clinical reproductive medicine research: 10 years of growth. Fertil Steril. 2015;104(1):131-7. Doi: 10.1016/j.fertnstert.2015.03.025. PMID: 25936232

4) Butler P, Khanna J. Assisted reproduction in developing countries-facing up to the issues. Prog Hum Reprod Res. 2003;63:1-8.

5) International Committee for Monitoring Assisted Reproductive Technologies (ICMART) press release, July 2012, ESHRE Istanbul, Turkey.

6) Sullivan E, Zegers-Hochschild F, Mansour R, Ishihara O, de Mouzon J, Nygren K. International Committee for Monitoring Assisted Reproductive Technologies (ICMART) world report: assisted reproductive technology 2004. Hum Reprod. 2013;28:1375-90.Doi:10.1093/humrep/det036. PMID:23442757

7) European Society of Human Reproduction and Embryology (ESHRE). 5 Million Babies. European Society of Human Reproduction and Embryology (ESHRE); 2012 [updated 2012; cited 2015 31.8]; Available from: http://www.eshre.eu/Press-Room/Press-releases/Press-releases-ESHRE-2012/5-million-babies.aspx.

8) Tulandi T, Shehata FF, DeCherney A. Fertility and Sterility and impact factor. Fertil Steril. 2010;93(7):2105-6. Doi:10.1016/j.fertnstert.2010.01.065. PMID: 20226446

9) Kremer JAM, Braat DDM, Evers JLH. Geographical distribution of publications in Human Reproduction and Fertility and Sterility in the 1990s. Hum Reprod. 2000;15(8):1653-6. Doi: 10.1093/humrep/15.8.1653, PMid:10920079

10) Andersen AN, Carlsen E, Loft A. Trends in the use of intracytoplasmatic sperm injection marked variability between countries. Hum Reprod Update. 2008;14(6):593-604. Doi: 10.1093/humupd/dmn032. PMID: 18708651

11) Griesinger G, Schultz L, Diedrich K. Publication productivity in IVF in Europe, 1990-2006. Reprod. Biomed. Online. 2009;19(4):452-5. PMID:19909584

12) GonzÃlez-Alcaide G, Aleixandre-Benavent R, Navarro-Molina C, Valderrama-ZuriÃn JC. Coauthorship networks and institutional collaboration patterns in reproductive biology. Fertil Steril. 2008;90(4):941-56. Doi:10.1016/j.fertnstert.2007.07.1378. PMID: 18177648.

13) Brandt JS, Downing AC, Howard DL, Kofinas JD, Chasen ST. Citation classics in obstetrics and gynecology: the 100 most frequently cited journal articles in the last 50 years. Am J Obstet Gynecol. 2010;203(4):355. e1-. e7. Doi: 10.1016/j.ajog.2010.07.025. PMID: 20875501

14) Evers JLH. 100 papers to read before you die. Hum Reprod. 2010;25(1):2-5. Doi: 10.1093/humrep/dep336.

15) Sembuya R. Mother or nothing: the agony of infertility. Bull World Health Organ. 2010;88:881-2. PMid:21124709, PMCid:PMC2995184

16) Ram S. Research Profile of Polycystic Ovary Syndrome: A Bibliometric Perspective of Literatures from 1984-2013. Collnet Journal of Scientometrics and Information Management. 2014;8(2):311-27. Doi: 10.1080/09737766.2014.954857

17) Brosens I. Are Catholic universities giving up reproductive medicine? Reprod Biomed Online. 2007;15:436. PMID: 18088520

18) Eskes T. The scientific output of a Catholic university department of obstetrics and gynecology. Reprod Biomed Online. 2008;17:7-10. PMID: 18644216. 